\title{
Depression and related factors after oral oncological treatment: a 5-year prospective cohort study
}

\author{
Caroline M. Speksnijder ${ }^{1,2,3}$ (D) Petra J. M. Lankhorst ${ }^{4} \cdot$ Remco de Bree $^{1} \cdot$ Anton F. J. de Haan $^{5} \cdot$ Ron Koole $^{4}$. \\ Matthias A. W. Merkx ${ }^{2}$
}

Received: 3 December 2019 / Accepted: 22 September 2020 / Published online: 1 October 2020

(C) The Author(s) 2020

\begin{abstract}
Purposes Being diagnosed with oral cancer is a life-threatening life event. It often induces social, emotional and psychological consequences and may cause depressive disorders. The primary aim of this study was to identify and quantify the personal and clinical characteristics involved in depression for patients who have been treated for oral cavity malignancies, with a 5-year follow-up period after treatment. The secondary aim of this study was to identify the clinical factors that increase a patient's risk of experiencing depression 5 years after treatment.

Methods Patients with primary oral cancer were assessed for up to 5 years after primary treatment. A mixed-model analysis was performed, with depression measured by the Center for Epidemiologic Studies Depression Scale as outcome measure.

Results A total of 141 patients were included in the study. Factors associated with depression were gender, tumour location and having an emotion-oriented coping style. The occurrence of depression within 5 years after treatment could be reliably predicted by a patient's gender, the location of their tumour and the extent to which they had an emotion-oriented coping style.

Conclusions This study revealed that being female, having a maxillary tumour and having an emotion-oriented coping style are associated with higher levels of depressive symptoms in patients treated for oral cancer up to 5 years post-treatment. A substantial proportion of the patients with oral cancer experienced high levels of depression both before and after their treatment, suggesting that adequate diagnostics and care are needed to try to prevent severe depression in these patients.
\end{abstract}

Keywords Oral cancer $\cdot$ Head and neck cancer $\cdot$ Depression $\cdot$ CES-D $\cdot$ Coping style $\cdot$ CISS-21

Caroline M. Speksnijder

c.m.speksnijder@umcutrecht.nl

1 Cancer Center, Department of Head and Neck Surgical Oncology, University Medical Center Utrecht, Utrecht University, Utrecht, The Netherlands

2 Department of Oral and Maxillofacial Surgery, Radboud University Medical Center, Nijmegen, The Netherlands

3 Department of Oral and Maxillofacial Surgery and Special Dental Care, University Medical Center Utrecht, Utrecht University, P.O. Box 85.500, 3508, GA Utrecht, The Netherlands

4 Department of Medical Oncology, Deventer Hospital, Deventer, The Netherlands

5 Department for Health Evidence, Section Biostatistics, Radboud University Medical Center, Nijmegen, The Netherlands

\section{Introduction}

Head and neck cancers are among the top ten most common causes of cancer-related deaths worldwide [1]. In the Netherlands, patients with oral cancer comprised of $28 \%$ of all patients with head and neck cancer [2]. Being diagnosed with oral cancer is a life-threatening life event. It often induces social, emotional and psychological consequences and may be associated with depressive disorders [3]. Depression is a common mental disorder in all patients with cancer [4]. The World Health Organization (WHO) defines depression as a disorder that lasts at least 2 weeks and is characterised by a person's persistent sadness, loss of interest in activities that he or she normally enjoys and an inability to perform daily activities [4]. In 2011, a meta-analysis was conducted on 66 studies to determine the prevalence of depression in people with cancer, revealing that major depression was reported in $16.3 \%(95 \%$ CI: $13-20 \%$ ) of these patients [5]. 
The oncological curative treatment of early-stage oral tumours usually involves surgery on indication, followed by radiotherapy and/or chemotherapy; however, these treatments and the resulting oral function deficits are associated with depression rates of $18 \%$ to $41 \%$ in patients treated for oral cancer [6-10]. A patient's diet and ability to speak are often affected by these treatments [11]. Depression is a risk marker for a long-term reduced quality of life $(\mathrm{QoL})$ in patients with oral cancer [12]. Previous studies have shown that personal and clinical characteristics, such as gender, age [13], marital status [14], education level, alcohol consumption [15], smoking behaviour [16], cancer stage [14] and cancer location [17], are factors associated with depression. Individual psychosocial characteristics, such as personality traits and coping styles, are also related to the depressive symptoms of patients with oral cancer [18-20].

To pursue an optimally targeted depression intervention, it is important to identity the risk factors for depression in patients with oral cancer [21-26]. The existing prospective cohort studies have a maximum follow-up of 1 to 3 years [17, $19,27,28]$; therefore, the primary aim of this study was to identify and quantify the personal and clinical characteristics involved in depression for patients who have been treated for oral cavity malignancies, with a 5 -year follow-up period after treatment. The secondary aim of this study was to identify the clinical factors that increase a patient's risk of experiencing depression 5 years after treatment. The tertiary aim was to identify and quantify the personal characteristics involved in depression in healthy persons.

\section{Methods}

\section{Subjects}

In this multi-centre prospective cohort research, the study population consisted of patients with a primary malignant tumour involving the oral cavity who were referred to the University Medical Center Utrecht (UMCU) or Radboud University Medical Center (Radboudumc) between January 2007 and August 2009. Patients were recruited at these medical centres before the oral oncological intervention. The eligibility criteria were the presence of primary malignant tumours involving the oral cavity. The exclusion criteria included a previous and/or current second primary malignancy, cognitive impairment and the inability to understand Dutch. Sixty healthy age-matched controls were measured once and recruited at the UMCU and 3 dental practices, whose details were published previously [29]. The study protocol (study ID: NL1200604106) was approved by the Ethics Committees of the UMCU and Radboudumc. All participants received written information with details regarding the study and provided their signed informed consent. All measurements took place at the place of recruitment (i.e. UMCU, Radboudumc or dental practice).

Radiotherapy was given in accordance with the Dutch Head and Neck Society treatment guidelines, with a total radiation dosage of 64 to $70 \mathrm{~Gy}$. Adjuvant radiotherapy, when given, started within 4 to 6 weeks after surgery.

The tumour locations of the oral cancers included the codes $\mathrm{C} 00, \mathrm{C} 02$ to $\mathrm{C} 06$ and $\mathrm{C} 31$ of the WHO International Classification of Diseases Oncology third edition (WHO ICD-0-3) [30]. Maxillary tumours included those on the upper alveolar process, tuber maxillae, palate and maxillary sinus (C03.0, C05, C31.0). Mandibular tumours included those on the lower alveolar process, the retromolar trigonum, the buccal mucosa and the lower lip (C00.4, C03.1, C06.0, C06.1, C06.2). Tongue and floor-of-the-mouth tumours included those located on the tongue and the anterior floor of the mouth (C02, C04) [30].

\section{Assessments}

Patients were assessed by filling in the Center for Epidemiologic Studies Depression Scale (CES-D) at a maximum of 4 weeks before their primary treatment (baseline, $t_{0}$ ); at 4 to 6 weeks after surgery $\left(t_{1 \mathrm{a}}\right)$ and/or 4 to 6 weeks after radiotherapy $\left(t_{1 \mathrm{~b}}\right)$; and at 6 months $\left(t_{2}\right), 1$ year $\left(t_{3}\right)$ and 5 years $\left(t_{4}\right)$ after their primary treatment.

Patient information, including gender, age, tumour location (maxilla, mandibula, tongue and/or floor of the mouth) and size (pT of TNM classification), resection site and details of reconstruction, were extracted from medical records. A maximum of 4 weeks before their primary treatment (baseline, $t_{0}$ ) body mass index (BMI; in $\mathrm{kg} / \mathrm{m}^{2}$ ), education level (primary education, secondary education, bachelor degree or master degree), living situation (living alone with or without children, with a partner with or without children), marital status (married or living together, unmarried, divorced or widowed), occupational status (working or not working), smoking status (current, former or non-smoker) and alcohol consumption (less than one unit per day, two to four units per day or more than five units per day) were charted by a questionnaire on paper. Patient coping styles were assessed by filling in the Coping Inventory for Stressful Situations-21 (CISS-21) on paper at $t_{0}$.

\section{Center for Epidemiologic Studies Depression Scale}

The main endpoint was the depression scores, which were determined using a questionnaire. At every assessment, the depressive symptoms were evaluated. The CES-D is a selfassessment questionnaire comprising 20 items [31]. Each item was scored on a 4-point Likert scale from seldom/never (0) to mostly/always (3), generating a range of 0 to 60 points in total. A higher score indicates a higher level of depression, with a 
CES-D score of 16 or more being considered a rough indicator of clinical depression in patients with oral cavity malignancies $[32,33]$. This rough indicator has not been completely validated but can be used as a cut-off point for clinical depression [34]. The CES-D has a good internal consistency, with a Cronbach's alpha score between 0.79 and 0.92 [34].

\section{Coping Inventory for Stressful Situations-21}

The CISS-21 questionnaire comprises seven items on task orientation, seven items on emotional orientation and seven items on avoidance coping [35]. Task-oriented coping refers to purposeful task-oriented efforts aimed at solving the problem, cognitively restructuring the problem or attempting to alter the situation. The emphasis is on the task or planning and attempts to solve the problem. Emotion-oriented coping refers to self-oriented emotional reactions, which include emotional responses, self-preoccupation and fantasising. Avoidance coping refers to activities and cognitive changes aimed at avoiding the stressful situation by distracting oneself with other situations or tasks, or via social diversion as a means of alleviating stress. Every item was scored on a 5point Likert scale ranging from not at all (0) to very often (4), with a score range of 0 to 28 per coping strategy. The higher the score for a coping strategy, the more dominant that coping strategy is in that person. CISS-21 is a shorter version of the original CISS questionnaire, which comprises 48 items and has been validated. The CISS-48 questionnaire has an internal consistency between 0.66 and 0.81 and a reliability between 0.65 and 0.78 [35]. The coping styles were evaluated at $t_{0}$ in this study.

\section{Statistical analysis}

Categorical patient characteristics are presented as numbers and percentages, while continuous characteristics are presented as means and standard deviations in the case of normally distributed variables. A mean imputation of the missing values was performed with continuous data and median with ordinal data. Because of the relatively few missing values $(0.58 \%)$, the mean and median imputation was not a distorted representation of the results. Differences between the baseline characteristics of patients in the different tumour location groups were analysed with a one-way ANOVA for continuous variables and a Chi-square test for categorical variables.

The mean values of the CES-D did not differ between the $t_{1 \mathrm{a}}$ and $t_{1 \mathrm{~b}}$ time points in patients who were treated with both surgery and radiotherapy; thus, only $t_{1 \mathrm{~b}}$ values for patients who had undergone both these assessments were included $\left(t_{1}\right)$.

A linear mixed-effects model with the CES-D score as the outcome was constructed to assess both the changes over time and the effect of the patient characteristics and clinical parameters in patients. To account for within-patient correlations, a random patient factor was added. Fixed-effect factors were assessed, including gender, age, tumour location, tumour size, BMI, education level, living situation, marital status, occupational status, smoking status, alcohol consumption and coping style, as were the two-way interactions of these factors with the assessment period. The factors that were not significant at a $p<0.05$ level were removed in a backward fashion, beginning with the interactions, to build a parsimonious model with sufficient fit while maintaining a hierarchical structure, meaning that if an interaction was included in the model, the main effects were also represented in the model. The coefficients of the significant covariates, together with the value of the intercept of the mixed model analysis, were combined into a formula for the estimated mean CES-D.

A multiple linear regression model was constructed for the CES-D at 5 years post-treatment. All significant variables from the above-mentioned mixed model were used in a multivariate binary logistic regression model to calculate the probability of depression (defined as CES-D $\geq 16$ ) after 5 years. A receiver operating characteristic (ROC) curve was constructed for this model to facilitate its use in the prediction of depression in our study group. A $p$ value $<0.05$ was considered statistically significant.

A linear regression with the CES-D score as the outcome was constructed to assess the effect of characteristics in the healthy persons. We considered several potential confounding factors: including gender, age, tumour location, tumour size, BMI, education level, living situation, marital status, occupational status, smoking status, alcohol consumption and coping style. For these variables, we performed unadjusted (i.e. for each variable separately) and adjusted analyses. The unadjusted analysis was performed to explore the potential association for each variable to CES-D. Afterwards, an adjusted model was constructed. Results were reported as regression coefficients with $95 \%$ CIs and $p$ values. A $p$ value of less than 0.05 was accepted as significant.

The mixed model analysis was performed using SAS version 9.4 (SAS institute, Cary, NC, USA). The remaining tests were performed using SPSS 25 (IBM Corp, Armonk, NY, USA).

\section{Results}

A total of 141 patients with the mean age of $65.6( \pm 12.8)$ were included in this prospective cohort study, 63 of whom were female (Table 1). Of these, 57 patients had undergone surgery, 20 had received radiotherapy, and 64 had received both surgery and radiotherapy. After 5 years, 71 patients were still participating in this study, 30 patients had stopped participating, 1 patient was excluded from the study because of recurrence of the tumour, and 39 had passed away (see also Fig. 1). Using the threshold CES-D score of 16 as an indicator for 
Table 1 Demographic and clinical characteristics of patients and healthy persons

\begin{tabular}{|c|c|c|c|c|c|}
\hline Patient characteristics, $n(\%)$ & Maxilla $(N=34)$ & Mandible $(N=53)$ & $\operatorname{TFM}(N=54)$ & $p$ Value & Healthy $(N=60)$ \\
\hline \multicolumn{6}{|l|}{ Sex } \\
\hline Female & $17(50.0)$ & $25(47.2)$ & $21(38.9)$ & \multirow[t]{2}{*}{$0.534^{\ddagger}$} & $29(48.3)$ \\
\hline Male & $17(50.0)$ & $28(52.8)$ & $33(61.1)$ & & $31(51.7)$ \\
\hline Age (years); mean (SD) & $68.4(12.2)$ & $66.6(12.4)$ & $62.3(13.0)$ & $0.059^{\ddagger}$ & $60.3(7.2)$ \\
\hline BMI; mean (SD) & $25.7(3.8)$ & $25.7(4.5)$ & $25.4(4.7)$ & $0.929^{\ddagger}$ & $25.2(3.7)$ \\
\hline \multicolumn{6}{|l|}{ Treatment } \\
\hline Surgery & $12(35.3)$ & $23(43.4)$ & $22(40.7)$ & \multirow[t]{3}{*}{$0.702^{\ddagger}$} & - \\
\hline Surgery and radiotherapy & $18(52.9)$ & $24(45.3)$ & $22(40.7)$ & & - \\
\hline Radiotherapy & $4(11.8)$ & $6(11.3)$ & $10(18.5)$ & & - \\
\hline \multicolumn{6}{|l|}{ Tumour size (T of TNM) } \\
\hline $\mathrm{T} 1$ & $5(14.7)$ & $16(30.2)$ & $23(42.6)$ & \multirow[t]{4}{*}{$0.014^{\ddagger}$} & - \\
\hline $\mathrm{T} 2$ & $11(32.4)$ & $13(24.5)$ & $16(29.6)$ & & - \\
\hline T3 & $1(2.9)$ & $3(5.7)$ & $6(11.1)$ & & - \\
\hline $\mathrm{T} 4$ & $17(50.0)$ & $21(39.6)$ & $9(16.7)$ & & - \\
\hline \multicolumn{6}{|l|}{ Surgical reconstruction } \\
\hline No reconstruction & $21(61.8)$ & $22(41.5)$ & $32(59.3)$ & \multirow[t]{4}{*}{$0.000 * * *^{*}$} & - \\
\hline Local flap & $1(2.9)$ & $2(3.8)$ & $1(1.9)$ & & - \\
\hline Free flap & $12(35.3)$ & $11(20.8)$ & $19(35.2)$ & & - \\
\hline Bone flap & $0(0.0)$ & $18(34.0)$ & $2(3.7)$ & & - \\
\hline \multicolumn{6}{|l|}{ Educational level } \\
\hline Elementary school & $8(23.5)$ & $11(20.8)$ & $7(13.0)$ & \multirow[t]{3}{*}{$0.299^{\ddagger}$} & $4(6.7)$ \\
\hline Secondary education & $18(53.0)$ & $35(66.0)$ & $32(59.3)$ & & $33(55.0)$ \\
\hline Higher education; $\geq$ bachelor & $8(23.5)$ & $7(13.2)$ & $15(27.8)$ & & $23(38.3)$ \\
\hline \multicolumn{6}{|l|}{ Living situation } \\
\hline Alone with/without children & $11(32.4)$ & $17(32.1)$ & $16(29.6)$ & \multirow[t]{2}{*}{$0.950^{\ddagger}$} & $3(5.0)$ \\
\hline With partner with/without children & $23(67.6)$ & $36(67.9)$ & $38(70.4)$ & & $57(95.0)$ \\
\hline \multicolumn{6}{|l|}{ Marital status } \\
\hline Married/living together & $23(67.6)$ & $34(64.2)$ & $37(68.5)$ & \multirow[t]{4}{*}{$0.069^{\ddagger}$} & $57(95.0)$ \\
\hline Unmarried & $2(5.9)$ & $3(5.7)$ & $11(20.4)$ & & $2(3.3)$ \\
\hline Divorced & $2(5.9)$ & $2(3.8)$ & $1(1.9)$ & & $0(0.0)$ \\
\hline Widowed & $7(20.6)$ & $14(26.4)$ & $5(9.3)$ & & $1(1.7)$ \\
\hline \multicolumn{6}{|l|}{ Occupational status } \\
\hline Paid work & $8(23.5)$ & $12(22.6)$ & $21(38.9)$ & \multirow[t]{2}{*}{$0.129^{\mathrm{a}}$} & $31(51.7)$ \\
\hline No work, retired & $26(76.5)$ & $41(77.4)$ & $33(61.1)$ & & $29(48.3)$ \\
\hline \multicolumn{6}{|l|}{ Smoking (daily) } \\
\hline Non-smoker & $11(32.4)$ & $12(22.6)$ & $11(20.4)$ & \multirow[t]{3}{*}{$0.770^{\ddagger}$} & $12(20.0)$ \\
\hline Former smoker & $12(35.3)$ & $20(37.7)$ & $21(38.9)$ & & $35(58.3)$ \\
\hline Current smoker & $11(32.4)$ & $21(39.6)$ & $22(40.7)$ & & $13(21.7)$ \\
\hline \multicolumn{6}{|l|}{ Alcohol use (daily) } \\
\hline No more than 1 unit & $25(73.5)$ & $37(69.8)$ & $30(55.6)$ & \multirow[t]{3}{*}{$0.155^{\ddagger}$} & $30(50.0)$ \\
\hline 2 to 4 units & $7(20.6)$ & $13(24.5)$ & $14(25.9)$ & & $27(45.0)$ \\
\hline More than 5 units & $2(5.9)$ & $3(5.7)$ & $10(18.5)$ & & $3(5.0)$ \\
\hline Task-orientation coping style; mean (SD) & $20.0(6.2)$ & $20.8(7.2)$ & $19.1(6.5)$ & $0.419^{\ddagger}$ & $19.4(5.9)$ \\
\hline Emotion-orientation coping style; mean (SD) & $10.9(3.3)$ & $11.1(4.3)$ & $12.2(4.9)$ & $0.279^{\ddagger}$ & $11.9(3.9)$ \\
\hline Avoidance coping style; mean (SD) & $13.1(3.7)$ & $12.6(4.1)$ & $13.8(5.2)$ & $0.341^{\ddagger}$ & $14.3(4.8)$ \\
\hline \multicolumn{6}{|l|}{ CES-D } \\
\hline Score $<16$ & $30(88.2)$ & $40(75.5)$ & $39(72.2)$ & \multirow[t]{2}{*}{$0.201^{\ddagger}$} & $53(88.3)$ \\
\hline Score $\geq 16$ & $4(11.8)$ & $13(24.5)$ & $15(27.8)$ & & $7(11.7)$ \\
\hline
\end{tabular}

${ }^{*} p<0.05 ; * * p<0.01 ; * * * p<0.001 ;{ }^{\ddagger}$ Chi-square test; ${ }^{\ddagger}$ ANOVA

$B M I$ body mass index, CES-D Center for Epidemiologic Studies Depression Scale, TFM tongue and/or floor of the mouth

clinical depression, $24.8 \%$ reported depression before the oncological treatment. At 1 and 5 years after the treatment, the symptoms of depression declined to $20.4 \%$ and $17.1 \%$, respectively. For the entire study population, the mean depression score before treatment was 11.4 and declined to 9.3 at 1 year after the treatment and to 8.6 at 5 years after the treatment. The healthy age matched controls reported depression for $11.7 \%$. The mean depression score of the healthy agematched controls was 10.3 .

\section{Depression in patients}

The mixed-model analysis showed that the type of treatment, tumour size, age, BMI, educational level, living situation, marital level, occupational status, smoking status and alcohol consumption did not significantly contribute to depression; therefore, these factors were removed from the model. Gender, tumour location and having an emotion-oriented coping style did significantly affect the likelihood of a patient 


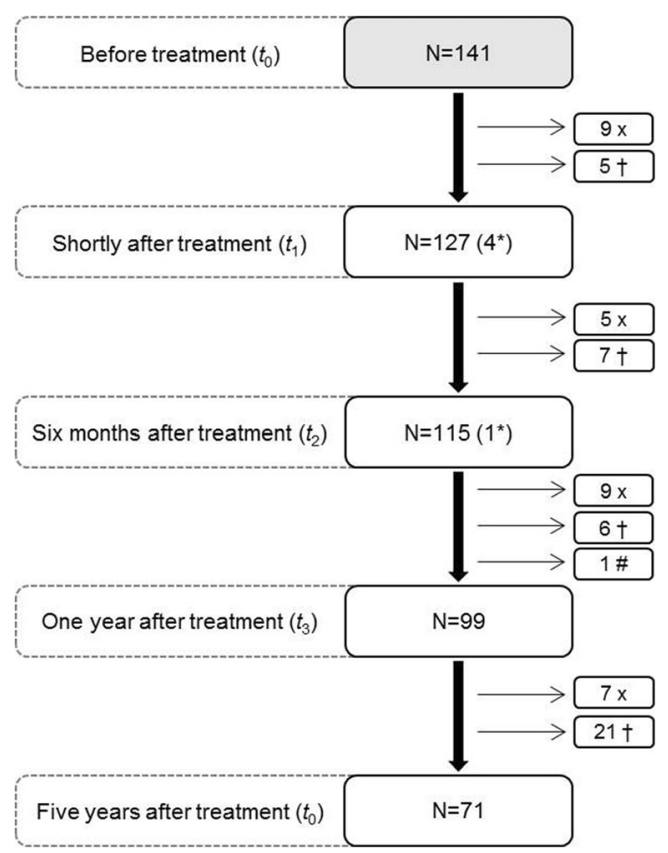

Fig. 1 Flowchart showing the number of measurements $(n)$ taken at each follow-up timepoint. X, patients stopped participating; $\uparrow$, patients passed away; \#, recurrence; *, missing measurement(s)

experiencing depression, with tumour location and an emotion-oriented coping style influencing depression differently at every assessment. This depression model is depicted in Table 2. Being a female was associated with higher scores on the CES-D depression scale.

After oncological treatment, patients with a maxillary tumour scored higher on the depression scale than patients with
Table 3 Logistic regression model for depression five years after treatment

\begin{tabular}{llll}
\hline & OR & $95 \%$ CI & $p$ Value \\
\hline $\begin{array}{l}\text { Gender } \\
\text { Tumour location }\end{array}$ & 0.6 & 0.1 to 2.3 & 0.416 \\
TFM & 1 & & \\
Maxilla & Non-estimable & N/A & 0.350 \\
Mandible & 3.0 & $(0.7$ to 13.1$)$ & \\
Emotion-oriented coping style & & \\
7 & 1 & N/A & $0.017^{*}$ \\
10 & 2.0 & $(1.1$ to 3.5$)$ & \\
17 & 9.8 & $(1.5$ to 63.4$)$ & \\
\hline
\end{tabular}

$* p<0.05 ;$ OR odds ratio, N/A not applicable, TFM tongue and/or floor of the mouth

a mandibular tumour. Patients with a tumour on the tongue and/or mouth floor scored lower on the depression scale than patients with a mandibular tumour. The patients with maxilla tumours had the highest increase on the depression scale at 4 to 6 weeks after their oncological treatment, which remained higher until half a year after the treatment. The same pattern is seen for patients with a tumour located at the mandible; however, this pattern is less pronounced. The location of the tumour had less of an impact on the depression scale score at the 1-year and 5-year follow-up assessments, but it is worth mentioning that 5 years after their treatment, patients with a maxilla tumour scored lower for depression than the other patients. A more emotion-orientated coping style resulted in a higher

Table 2 The significant coefficients and interactions derived from the mixed model procedure for depression

\begin{tabular}{|c|c|c|c|c|c|c|c|c|c|c|c|c|c|}
\hline & \multirow{2}{*}{$\begin{array}{l}\text { Mixed model } \\
\text { Intercept }\end{array}$} & \multirow{2}{*}{$\begin{array}{l}\text { Main effects } \\
1.399\end{array}$} & \multirow{2}{*}{$\begin{array}{l}\text { SE } \\
2.751\end{array}$} & \multicolumn{10}{|c|}{ Interactions with the assessment moment } \\
\hline & & & & & & & & & & & & & \\
\hline & & & & Before & SE & After & SE & 6 months & SE & 1 year & SE & 5 years & $\mathrm{SE}$ \\
\hline \multirow[t]{5}{*}{ Assessment moment } & Before & -3.022 & 2.755 & & & & & & & & & & \\
\hline & After & -0.012 & 2.776 & & & & & & & & & & \\
\hline & 6 Months & -0.450 & 2.802 & & & & & & & & & & \\
\hline & 1 Year & -1.882 & 2.938 & & & & & & & & & & \\
\hline & 5 Years & 0 & 0 & & & & & & & & & & \\
\hline \multirow[t]{2}{*}{ Sex } & Female & 2.657 & 1.021 & & & & & & & & & & \\
\hline & Male & 0 & 0 & & & & & & & & & & \\
\hline \multirow[t]{3}{*}{ Tumour location } & Maxilla & -2.201 & 2.120 & 1.522 & 2.127 & 5.771 & 2.151 & 7.467 & 2.197 & 4.907 & 2.242 & 0 & 0 \\
\hline & Mandible & 2.602 & 1.845 & -1.165 & 1.855 & -0.413 & 1.868 & 0.864 & 1.888 & -0.410 & 1.929 & 0 & 0 \\
\hline & TFM & 0 & 0 & 0 & 0 & 0 & 0 & 0 & 0 & 0 & 0 & 0 & 0 \\
\hline Emotion-orientation coping & & 0.539 & 0.208 & 0.454 & 0.209 & 0.090 & 0.211 & -0.062 & 0.212 & 0.104 & 0.227 & 0 & 0 \\
\hline
\end{tabular}

Coefficients and SE obtained with the mixed model analysis. Main effect of each independent factor is detailed on the "main effects" row. Significant interactions between factors and assessment moment are shown on the "interactions" row. In order to apply these results on practice, coefficients of categorical values should be multiplied by " 1 " when present and by " 0 " when absent. Coefficients of continuous variables should be multiplied by the outcome of that factor 
Table 4 Probability of depression five years after treatment (based on gender, tumour location and level of emotion-oriented coping style) according to the logistic regression model

\begin{tabular}{|c|c|c|c|c|c|c|c|}
\hline \multirow[t]{2}{*}{ Emotion-oriented coping style } & \multirow[t]{2}{*}{ Gender } & \multicolumn{2}{|c|}{ Maxilla } & \multicolumn{2}{|c|}{ Mandible } & \multicolumn{2}{|l|}{ TFM } \\
\hline & & & $95 \% \mathrm{CI}$ & & $95 \% \mathrm{CI}$ & & $95 \% \mathrm{CI}$ \\
\hline \multirow[t]{2}{*}{7 (P10) } & Female & $0 \%$ & $(0-100)$ & $17 \%$ & $(5-49)$ & $7 \%$ & $(1-31)$ \\
\hline & Male & $0 \%$ & $(0-100)$ & $10 \%$ & $(3-34)$ & $4 \%$ & $(1-18)$ \\
\hline \multirow[t]{2}{*}{10 (P50) } & Female & $0 \%$ & $(0-100)$ & $30 \%$ & $(11-59)$ & $12 \%$ & $(3-39)$ \\
\hline & Male & $0 \%$ & $(0-100)$ & $19 \%$ & $(6-44)$ & $7 \%$ & $(2-24)$ \\
\hline \multirow[t]{2}{*}{17 (P90) } & Female & $0 \%$ & $(0-100)$ & $67 \%$ & $(31-91)$ & $41 \%$ & $(14-76)$ \\
\hline & Male & $0 \%$ & $(0-100)$ & $53 \%$ & $(19-85)$ & $28 \%$ & $(9-61)$ \\
\hline
\end{tabular}

TFM tongue and/or floor of the mouth score on the depression scale, which was most pronounced before the intervention.

\section{Probability of depression 5 years after treatment}

The combination of gender, tumour location and having an emotion-oriented coping style yielded the largest correlation coefficient in the multiple linear regression model for CES-D at 5 years post-treatment. These three variables were used in a logistical regression to calculate the probability of having a depression 5 years after treatment (Table 3). Having an emotion-oriented coping style (at least 17 points) was the highest risk factor for depression at this time point (1/odds

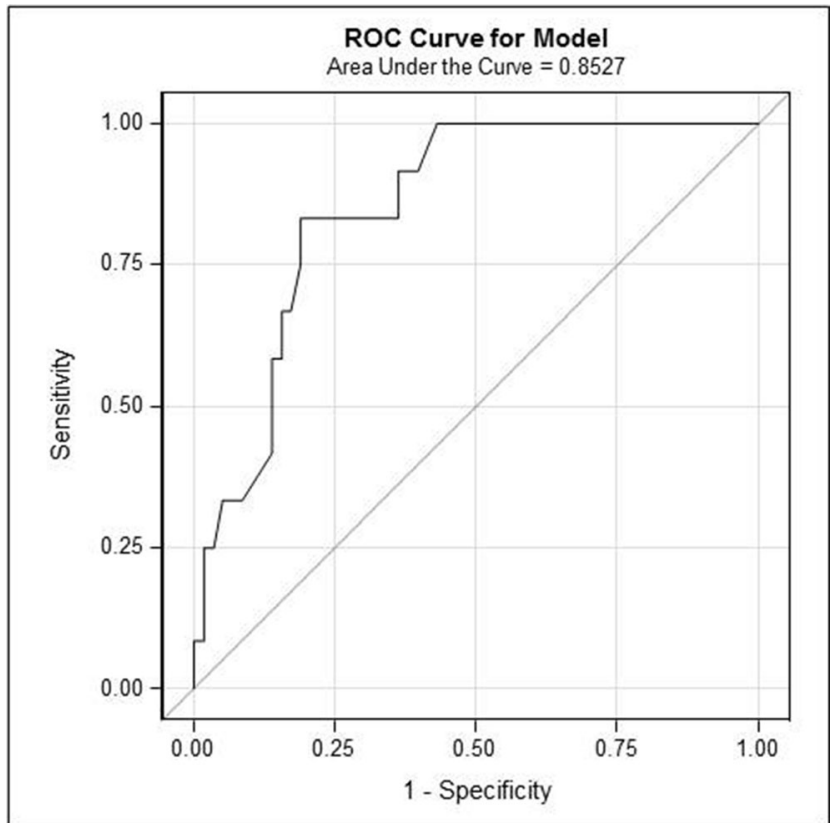

Fig. 2 A receiver operating characteristic (ROC) curve for the prediction of depression 5 years after treatment using the logistic regression model (based on gender, tumour location and emotion-oriented coping style). The area under the curve is 0.8297 . Areas under the curve can vary between 0 and 1 ; a value of 0.5 indicates that the model has no diagnostic power, while a 1 indicates that the model has perfect diagnostic accuracy ratio [OR], 0.10204 per point); thus, the probability of developing depression is higher with a strongly emotionally oriented coping style. The other risk factor at the 5-year follow-up appointment was having had a mandibular tumour (OR 3.0). Table 4 summarises the probability of developing depression within 5 years for three patient groups with emotional coping style scores of 7 (P10), 10 (P50) or 17 points (P90). Using this statistical method to predict depression after 5 years yielded an area under ROC of 0.8297 (Fig. 2).

\section{Depression in healthy persons}

In the unadjusted linear regression models, only emotionoriented coping style was associated with depression $(p=$ 0.006; Table 5). Therefore, the adjusted model did not differ from the unadjusted model for emotion-oriented coping style. The effect of emotion-oriented coping style results in an increase of 0.527 points on the CES-D for each point on the emotion-oriented coping style scale (95\% CI: 0.154-0.901). So the more the coping style of a person is emotion-oriented, the higher is the level of depression.

\section{Discussion}

Gender, tumour location and having an emotion-oriented coping style were identified as characteristics involving depression in patients treated for oral cancer. At 1 and 5 years after the treatment, the prevalence of depression decreased. The occurrence of depression (defined as CES-D $\geq 16$ ) within 5 years after treatment could be reliably predicted by a patient's gender, the location of their tumour and the extent to which they had an emotion-oriented coping style. Emotion-oriented coping style was also identified as characteristic involving depression in the healthy age-matched controls.

Of the healthy age-matched controls, $11.7 \%$ had depression (CES-D $\geq 16$ ), while $24.8 \%$ of the patients with oral cancer reported having depression before their oncological treatment, and $20.4 \%$ and $17.1 \%$, respectively, had depression 
Table 5 Adjusted and unadjusted linear regression model for depression in healthy persons

\begin{tabular}{|c|c|c|c|c|}
\hline Variable & $\begin{array}{l}\text { Unadjusted regression coefficients ( } 95 \% \\
\text { CI) }\end{array}$ & $p$ Value & $\begin{array}{l}\text { Adjusted model regression coefficients ( } 95 \% \\
\text { CI) }\end{array}$ & $p$ Value \\
\hline \multicolumn{5}{|l|}{ Sex } \\
\hline Female & $2.107(-0.919-5.133)$ & 0.169 & & \\
\hline Male & 0 & & & \\
\hline Age (years) & $-0.049(-0.263-0.165)$ & 0.648 & & \\
\hline BMI & $-0.218(-0.636-0.199)$ & 0.300 & & \\
\hline \multicolumn{5}{|l|}{ Educational level } \\
\hline Elementary school & $3.848(-2.548-10.243)$ & 0.233 & & \\
\hline Secondary education & $-0.622(-3.829-2.585)$ & 0.699 & & \\
\hline $\begin{array}{l}\text { Higher education; } \geq \text { bachelor } \\
\text { degree }\end{array}$ & 0 & & & \\
\hline \multicolumn{5}{|l|}{ Living situation } \\
\hline Alone with/without children & $5.018(-1.912-11.947)$ & 0.153 & & \\
\hline With partner with/without children & 0 & & & \\
\hline \multicolumn{5}{|l|}{ Marital status } \\
\hline Married/living together & $-1.684(-13.542-10.174)$ & 0.777 & & \\
\hline Unmarried & $5.000(-9.397-19.397)$ & 0.490 & & \\
\hline Divorced & - & - & & \\
\hline Widowed & 0 & & & \\
\hline \multicolumn{5}{|l|}{ Occupational status } \\
\hline Paid work & $-1.706(-4.750-1.337)$ & 0.266 & & \\
\hline No work, retired & 0 & & & \\
\hline \multicolumn{5}{|l|}{ Smoking (daily) } \\
\hline Non-smoker & $-1.897(-6.653-2.858)$ & 0.428 & & \\
\hline Former smoker & $-2.202(-6.061-1.656)$ & 0.258 & & \\
\hline Current smoker & 0 & & & \\
\hline \multicolumn{5}{|l|}{ Alcohol use (daily) } \\
\hline No more than 1 unit & $-6.933(-13.935-0.068)$ & 0.052 & & \\
\hline 2 to 4 units & $-5.111(-12.148-1.926)$ & 0.151 & & \\
\hline More than 5 units & 0 & & & \\
\hline Task-orientation coping style & $0.170(-0.089-0.428)$ & 0.193 & & \\
\hline Emotion-orientation coping style & $0.527(0.154-0.901)$ & $0.006 * *$ & $0.527(0.154-0.901)$ & $0.006 * *$ \\
\hline Avoidance coping style & $0.178(-0.141-0.498)$ & 0.268 & & \\
\hline Intercept & & & $4.281(-0.400-8.961)$ & \\
\hline$R^{2}$ & & & & 0.121 \\
\hline
\end{tabular}

$* * p<0.01 ; C I$ confidence interval. The unadjusted model showed the association of each variable to depression. The adjusted model showed depression and emotion-orientation coping style of healthy persons $\left(R^{2}=0.121\right)$

at 1 and 5 years after the treatment. This revealed that patients with oral cancer had a higher prevalence of depression than the healthy controls, although this did decrease over time after their treatment. In the Longitudinal Aging Study Amsterdam, it was shown that persons between 64 and 84 years had a depression prevalence of $12.5 \%$ to $16.6 \%$, which is also less than the prevalence's we found before and up to 1 year after oral cancer treatment [36]. Thereby, the levels of depressive symptoms in our study were consistent with the results of other studies on depression rates in patients with cancer; for example, the published literature also showed that the mean depression score for the population of patients with cancer rises 3 to 6 months after treatment and starts to decrease 1 year after treatment [37]. Currently, no published studies have determined the depression risk for patients at 5 years after oral cancer treatment. In clinic we experience that patients who survived oral cancer get used to their remaining deficits and are becoming less afraid of dying from cancer. Patients may therefore show a decreasing depression rate starting at 1 year after their oncological intervention.

Here, we showed that patients treated for a maxilla tumour were significantly more likely to develop depression shortly after treatment than the other patients. Shortly after treatment, patients requiring an obturator prosthesis often do not have yet 
their final prostheses, which can limit speech [38], eating [39] and influence the mood of the patients.

This study showed that female patients had a significantly higher risk for clinical depression, which is in line with the current literature [40]. This finding might have resulted from biological factors (such as hormones) and social factors; for example, the experience of stress may be different for females than males [41], but also disfigurement may be different for females than males [42]. On the other hand, being a male is a protective factor for clinical depression based on the results of this study.

In addition, this study showed that a higher emotionoriented coping style significantly increases the risk of developing depression in both patients and healthy age-matched controls. According to the current literature, increases in depression symptoms are related to a person's preference for emotion-oriented rather than task-oriented coping strategies [43], which was consistent with our findings.

Two of the cohort study's strengths are the longitudinal design and the implementation of the 5-year post-treatment follow-up assessment. No previous study has presented the depression rates of oral cancer patients 5 years after treatment. We included a broad range of patient characteristics and coping strategies that could potentially predict the depressive symptoms of patients before treatment to 5 years after treatment. Moreover, another strength of the cohort study is the generalisability of the study population. The patients were recruited from two of the eight academic head and neck cancer centres in the Netherlands. To fully appreciate the present results, some additional points must be considered. First, given that this study has no experimental aspect, it is not clear whether the patient was treated for possible depressive symptoms by, for example, their general practitioner, or if any other interventions were used to prevent or treat depressive symptoms. In addition, the depression scale, coping questionnaire and patient characteristics were self-reported, which could have resulted in underreported effects [44]. Furthermore, the CISS-21 questionnaire is a shorter version of the validated CISS-48 questionnaire and has not been completely validated in its own right.

The findings of this study could be used to enable nurses to recognise patients with oral cancer who are at a higher risk for depression, allowing them to enact measures to prevent them from developing severe depression. These results could also be used to optimise the counselling treatments provided by nurses, which has been proven to be effective at reducing depressive symptoms by providing information about the use of effective coping styles [45]. It is therefore essential to train nurses in how to accurately use depression-screening instruments.

Future prospective studies should test whether the number of depressive symptoms (CES-D scores) is related to the quality of oral functioning, the QoL and the amount of disfigurement. It is also important to consider whether the type of nursing intervention fits with the counselling of different patient characteristics that predict depression. Thus, this study should be repeated while implementing a validated coping questionnaire, which would provide nurses with effective information about the coping styles used by patients with oral cancer.

In conclusion, this study revealed that being female, having a maxillary tumour and having an emotion-oriented coping style are associated with higher levels of depressive symptoms in patients treated for oral cancer up to 5 years post-treatment. A substantial proportion of the patients with oral cancer experienced high levels of depression both before and after their treatment, suggesting that adequate diagnostics and care are needed to try to prevent severe depression in these patients. In healthy persons an emotion-oriented coping style is also associated with higher levels of depressive symptoms; however, the effect is smaller than in patients treated for oral cancer.

Data availability The authors have full control of all primary data and agree to allow the journal view primary data upon request.

\section{Compliance with ethical standards}

Conflict of interest The authors declare that they have no conflict of interest.

Ethics approval The study protocol is in accordance with the Declaration of Helsinki, 1964, as revised in 1975, 1983, 1989, 1996 and 2000, and was approved by the Research Ethics Committee of UMC Utrecht and Radboudumc (study ID NL1200604106).

Open Access This article is licensed under a Creative Commons Attribution 4.0 International License, which permits use, sharing, adaptation, distribution and reproduction in any medium or format, as long as you give appropriate credit to the original author(s) and the source, provide a link to the Creative Commons licence, and indicate if changes were made. The images or other third party material in this article are included in the article's Creative Commons licence, unless indicated otherwise in a credit line to the material. If material is not included in the article's Creative Commons licence and your intended use is not permitted by statutory regulation or exceeds the permitted use, you will need to obtain permission directly from the copyright holder. To view a copy of this licence, visit http://creativecommons.org/licenses/by/4.0/.

\section{References}

1. Chaturvedi AK, Anderson WF, Lortet-Tieulent J, Curado MP, Ferlay J, Franceschi S, Rosenberg PS, Bray F, Gillison ML (2013) Worldwide trends in incidence rates for oral cavity and oropharyngeal cancers. J Clin Oncol 31:4550-4559. https://doi. org/10.1200/JCO.2013.50.3870

2. Integraal Kankercentrum Nederland (2020) Meest voorkomende soorten kanker; cijfers over kanker. www.iknl.nl

3. Haisfield-Wolfe ME, McGuire DB, Soeken K et al (2012) Prevalence and correlates of symptoms and uncertainty in illness among head and neck cancer patients receiving definitive radiation 
with or without chemotherapy. Support Care Cancer 20:18851893. https://doi.org/10.1007/s00520-011-1291-9

4. Mitchell AJ, Chan M, Bhatti et al (2011) Prevalence of depression, anxiety, and adjustment disorder in oncological, haematological, and palliative-care settings: a meta-analysis of 94 interview-based studies. Lancet Oncol 12:160-174

5. Mitchell AJ, Chan M, Bhatti H, Halton M, Grassi L, Johansen C, Meader N (2011) Prevalence of depression, anxiety, and adjustment disorder in oncological, haematological, and palliative-care settings: a meta-analysis of 94 interview-based studies. Lancet Oncol 12:160-174. https://doi.org/10.1016/S1470-2045(11)70002-X

6. Moore KA, Ford PJ, Farah CS (2014) Support needs and quality of life in oral cancer: a systematic review. Int J Dent Hyg 12:36-47. https://doi.org/10.1111/idh.12051

7. Hassanein KAAM, Musgrove BT, Bradbury E (2005) Psychological outcome of patients following treatment of oral cancer and its relation with functional status and coping mechanisms. J Cranio-Maxillofac Surg 33:404-409. https://doi.org/10.1016/j. jcms.2005.05.005

8. Pandey M, Devi N, Thomas BC, Vinod Kumar S, Krishnan R, Ramdas K (2007) Distress overlaps with anxiety and depression in patients with head and neck cancer. Psychooncology 16:582586. https://doi.org/10.1002/pon.1123

9. Verdonck-de Leeuw IM, de Bree R, Keizer AL, Houffelaar T, Cuijpers P, van der Linden MH, Leemans CR (2009) Computerized prospective screening for high levels of emotional distress in head and neck cancer patients and referral rate to psychosocial care. Oral Oncol 45:e129-e133. https://doi.org/10.1016/ j.oraloncology.2009.01.012

10. Morton RP, Davies AD, Baker J et al (1984) Quality of life in treated head and neck cancer patients: a preliminary report. Clin Otolaryngol Allied Sci 9:181-185

11. Speksnijder CM, van der Glas HW, van der Bilt A, van Es RJJ, van der Rijt E, Koole R (2010) Oral function after oncological intervention in the oral cavity: a retrospective study. J Oral Maxillofac Surg 68:1231-1237. https://doi.org/10.1016/j.joms.2009.09.016

12. Rana M, Gellrich N-C, Rana M (2015) Comparison of healthrelated quality of life of patients with different precancer and oral cancer stages. Clin Oral Investig 19:481-488. https://doi.org/10. 1007/s00784-014-1265-7

13. Hammerlid E, Ahlner-Elmqvist M, Bjordal K, Biörklund A, Evensen J, Boysen M, Jannert M, Kaasa S, Sullivan M, Westin T (1999) A prospective multicentre study in Sweden and Norway of mental distress and psychiatric morbidity in head and neck cancer patients. Br J Cancer 80:766-774. https://doi.org/10.1038/sj.bjc. 6690420

14. Espie CA, Freedlander E, Campsie LM, Soutar DS, Robertson AG (1989) Psychological distress at follow-up after major surgery for intra-oral cancer. J Psychosom Res 33:441-448

15. Kugaya A, Akechi T, Okuyama T et al (2000) Prevalence, predictive factors, and screening for psychologic distress in patients with newly diagnosed head and neck cancer. Cancer 88:2817-2823. https://doi.org/10.1002/1097-0142(20000615)88:12<2817::AIDCNCR22>3.0.CO;2-N

16. Duffy SA, Terrell JE, Valenstein $M$ et al Effect of smoking, alcohol, and depression on the quality of life of head and neck cancer patients. Gen Hosp Psychiatry 24:140-147

17. de Leeuw JR, de Graeff A, Ros WJ, Blijham GH, Hordijk GJ, Winnubst JA (2001) Prediction of depression 6 months to 3 years after treatment of head and neck cancer. Head Neck 23:892-898

18. de Leeuw J, de Graeff A, Ros WJ et al (2000) Negative and positive influences of social support on depression in patients with head and neck cancer: a prospective study. Psychooncology 9:20-28

19. de Graeff A, de Leeuw JRJ, Ros WJG et al (2000) Pretreatment factors predicting quality of life after treatment for head and neck cancer. Head Neck 22:398-407. https://doi.org/10.1002/10970347(200007)22:4<398::AID-HED14>3.0.CO;2-V

20. Verdonck-de Leeuw IM, Eerenstein SE, Van der Linden MH et al (2007) Distress in spouses and patients after treatment for head and neck cancer. Laryngoscope 117:238-241. https://doi.org/10.1097/ 01.mlg.0000250169.10241.58

21. McDowell I (2006) Measuring health: a guide to rating scales and questionnaires. Oxford University Press, New York

22. Lin BM, Starmer HM, Gourin CG (2012) The relationship between depressive symptoms, quality of life, and swallowing function in head and neck cancer patients 1 year after definitive therapy. Laryngoscope 122:1518-1525. https://doi.org/10.1002/lary.23312

23. Strong V, Waters R, Hibberd C, Murray G, Wall L, Walker J, McHugh G, Walker A, Sharpe M (2008) Management of depression for people with cancer (SMaRT oncology 1): a randomised trial. Lancet 372:40-48. https://doi.org/10.1016/S0140-6736(08) 60991-5

24. Sharpe M, Walker J, Hansen CH, Martin P, Symeonides S, Gourley C, Wall L, Weller D, Murray G (2014) Integrated collaborative care for comorbid major depression in patients with cancer (SMaRT Oncology-2): A multicentre randomised controlled effectiveness trial. Lancet 384:1099-1108. https://doi.org/10.1016/S01406736(14)61231-9

25. Walker J, Hansen CH, Martin P, Symeonides S, Gourley C, Wall L, Weller D, Murray G, Sharpe M, SMaRT (Symptom Management Research Trials) Oncology-3 Team (2014) Integrated collaborative care for major depression comorbid with a poor prognosis cancer (SMaRT Oncology-3): a multicentre randomised controlled trial in patients with lung cancer. Lancet Oncol 15:1168-1176. https://doi. org/10.1016/S1470-2045(14)70343-2

26. Van Der Meulen IC, May AM, De Leeuw JRJ et al (2014) Longterm effect of a nurse-led psychosocial intervention on healthrelated quality of life in patients with head and neck cancer: a randomised controlled trial. Br J Cancer 110:593-601. https://doi. org/10.1038/bjc. 2013.733

27. Aarstad HJ, Aarstad AKH, Heimdal J-H, Olofsson J (2005) Mood, anxiety and sense of humor in head and neck cancer patients in relation to disease stage, prognosis and quality of life. Acta Otolaryngol 125:557-565

28. Derks W, De Leeuw R, Winnubst J, Hordijk GJ (2004) Elderly patients with head and neck cancer: physical, social and psychological aspects after 1 year. Acta Otolaryngol 124:509-514. https://doi. org/10.1080/00016480310000656

29. Speksnijder CM, Abbink JH, Van Der Glas HW et al (2009) Mixing ability test compared with a comminution test in persons with normal and compromised masticatory performance. Eur J Oral Sci 117:117-586. https://doi.org/10.1111/j.1600-0722.2009. 00675.x

30. WHO (2000) International classification of diseases for oncology, 3rd (ICD-O). World Health Organization, Switzerland

31. Radloff LS (1977) The CES-D scale: a self-report depression scale for research in the general population. Appl Psychol Meas 1:385401

32. Schroevers MJ, Sanderman R, van Sonderen E, Ranchor AV (2000) The evaluation of the Center for Epidemiologic Studies Depression (CES-D) scale: depressed and positive affect in cancer patients and healthy reference subjects. Qual Life Res 9:1015-1029

33. Bouma J, Ranchor AV, Sanderman R, Van Sonderen E (2012) Het meten van symptomen van depressie met de CES-D. Research Institute SHARE, UMCG/ RUG, Groningen

34. Wijnhoven LAMW, Creemers DHM, Vermulst AA, Scholte RHJ, Engels RCME (2014) Randomized controlled trial testing the effectiveness of a depression prevention program ('op volle kracht') among adolescent girls with elevated depressive symptoms. J Abnorm Child Psychol 42:217-228. https://doi.org/10.1007/ s10802-013-9773-5 
35. Endler NS, Parker JDA (1990) CISS | Coping Inventory for stressful situation. Swets Test Publishers, Lisse

36. Timmermans EJ, Hoogendijk EO, Broese Van Groenou MI et al (2019) Trends across 20 years in multiple indicators of functioning among older adults in the Netherlands. Eur J Pub Health 29:10961102. https://doi.org/10.1093/eurpub/ckz065

37. Tempelaar R, de Ruiter H, van Sonderen E, Sanderman R, Legtenberg A (1994). Kanker en sociale relaties. Verslag van een onderzoek naar het belang van sociale relaties van kankerpatienten. Groningen: Vakgroep Gezondheidswetenschappen RUG/ Noordelijk Centrum voor Gezondheidsvraagstukken

38. Rieger JM, Wolfaardt JF, Jha N, Seikaly H (2003) Maxillary obturators: the relationship between patient satisfaction and speech outcome. Head Neck 25:895-903

39. Kreeft AM, Krap M, Wismeijer D, Speksnijder CM, Smeele LE, Bosch SD, Muijen MSA, Balm AJM (2012) Oral function after maxillectomy and reconstruction with an obturator. Int J Oral Maxillofac Surg 41:1387-1392. https://doi.org/10.1016/j.ijom. 2012.07.014

40. Katz MR, Irish JC, Devins GM, Rodin GM, Gullane PJ (2003) Psychosocial adjustment in head and neck cancer: the impact of disfigurement, gender and social support. Head Neck 25:103112. https://doi.org/10.1002/hed.10174

41. Denenrstein L, Astbury J, Morse C (1993) psychosocial and mental health aspects of women's health. World Heal Organisation, Geneva
42. Ellis MA, Sterba KR, Brennan EA et al (2019) A systematic review of patient-reported outcome measures assessing body image disturbance in patients with head and neck cancer. Otolaryngol Head Neck Surg 160:941-954

43. Li C, Liu Q, Hu T, Jin X (2017) Adapting the short form of the coping inventory for stressful situations into Chinese. Neuropsychiatr Dis Treat 13:1669-1675. https://doi.org/10.2147/ NDT.S136950

44. Short ME, Goetzel RZ, Pei X, Tabrizi MJ, Ozminkowski RJ, Gibson TB, DeJoy DM, Wilson MG (2009) How accurate are self-reports? Analysis of self-reported health care utilization and absence when compared with administrative data. J Occup Environ Med 51:786-796. https://doi.org/10.1097/JOM. 0b013e3181a86671

45. Meulen IC, May AM, Ros WJG, Oosterom M, Hordijk GJ, Koole R, Leeuw JRJ (2013) One-year effect of a nurse-led psychosocial intervention on depressive symptoms in patients with head and neck cancer: a randomized controlled trial. Oncologist 18:336344. https://doi.org/10.1634/theoncologist.2012-0299

Publisher's note Springer Nature remains neutral with regard to jurisdictional claims in published maps and institutional affiliations. 